\author{
BIODIVERSITY OBSERVATIONS \\ RESEARCH PAPER (MORTALITY AND DistRIBUTION)
}

\title{
Leopard tortoise (Stigmochelys pardalis) road mortality and extralimital occurrence in Western Cape, South Africa.
}

Author(s):

Baxter-Gilbert J, and Riley JL
Journal editor:

Pete Laver

Manuscript editor:

Pete Laver

Received: March 23, 2019; Accepted: December 24, 2019; Published: December 24, 2019

Citation: Baxter-Gilbert J, and Riley JL. 2019. Leopard tortoise (Stigmochelys pardalis) road mortality and extralimital occurrence in Western Cape, South Africa.. Biodiversity Observations 10.12:1-4

Journal: https://journals.uct.ac.za/index.php/BO/

Manuscript: https://journals.uct.ac.za/index.php/BO/article/view/732

PDF: https://journals.uct.ac.za/index.php/BO/article/view/732/648

HTML: http://thebdi.org/blog/2019/12/24/leopard-tortoise-road-mortality
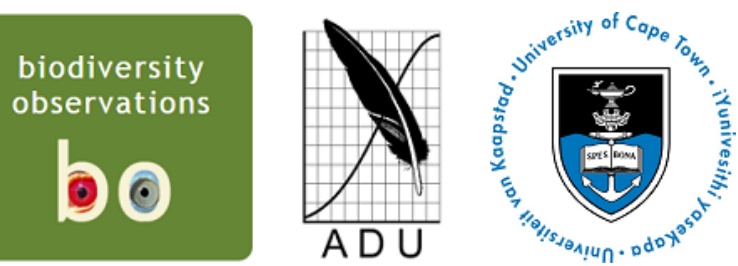

Biodiversity Observations is an open access electronic journal published by the Animal Demography Unit at the University of Cape Town, available at https://journals.uct.ac.za/index.php/BO/

The scope of Biodiversity Observations includes papers describing observations about biodiversity in general, including animals, plants, algae and fungi. This includes observations of behaviour, breeding and flowering patterns, distributions and range extensions, foraging, food, movement, measurements, habitat and colouration/plumage variations. Biotic interactions such as pollination, fruit dispersal, herbivory and predation fall within the scope, as well as the use of indigenous and exotic species by humans. Observations of naturalised plants and animals will also be considered. Biodiversity Observations will also publish a variety of other interesting or relevant biodiversity material: reports of projects and conferences, annotated checklists for a site or region, specialist bibliographies, book reviews and any other appropriate material. Further details and guidelines to authors are on the journal website (https://journals.uct.ac.za/index.php/BO/). 


\section{Leopard tortoise (Stigmochelys pardalis) road mortality and extralimital occurrence in Western Cape, South Africa.}

James Baxter-Gilbert Centre of Excellence for Invasion Biology, Department of Botany and Zoology, Stellenbosch University, Stellenbosch, South Africa, 7600, ORCID ID 0000-0002-1283-8893

Julia L. Riley Department of Botany and Zoology, Stellenbosch University, Stellenbosch, South Africa, 7600, ORCID ID 0000-0001-7691-691

On 8 October 2018 at 16:10 h, while driving along the R364 Highway $6 \mathrm{~km}$ west of Lambert's Bay, Western Cape, South Africa $\left(32.0978^{\circ} \mathrm{S}, 18.3267^{\circ} \mathrm{E}\right)$, we observed a deceased leopard tortoise (Stigmochelys pardalis) on the side of the road. The tortoise had been struck by a vehicle, with the carapace split along the spine and both bridges of the shell fractured (Fig. 1). The specimen we observed was a medium-sized female (straight-line plastron length of 310 $\mathrm{mm}$ and a reconstructed straight-line carapace length of approximately $390 \mathrm{~mm}$ ). Tortoise and turtle road mortality is not uncommon, and is often cited as a major contributor to population declines for many species across the globe (Gibbs and Shriver 2002; Aresco 2005; Andrews et al. 2008). Yet, for the leopard tortoise, road mortality is considerably under-reported (but see Dean and Milton 2003). We later observed a second adult female leopard tortoise crossing a nearby dirt road $3 \mathrm{~km}$ west of Lambert's Bay (Fig. 2) on 13 November 2018 at 16:35 h. This individual was moved off the road in the direction it was travelling to prevent it suffering the same fate as the previous individual we observed.

A study assessing driver attitudes on animal-vehicle collisions in Northern Tanzania, found that drivers said they were least likely to hit leopard tortoises due to the perceived damage it could cause to their vehicles (Kioko et al. 2015), as they are one of the largest species of tortoise on the continent (Boycott and Bourquin 2000). However, as our observation notes, vehicle collisions with leopard tortoises do occur. The direct effect of road mortality has a high likelihood of effecting many African reptile populations, especially for long-lived species with low recruitment rates that are negatively impacted over the long-term by small increases in adult mortality (e.g., turtles and tortoises, Gibbs and Shriver 2002; Keevil et al. 2018). There may also be indirect impacts of roads on leopard tortoises. For example, poaching rates may be increased by tortoises' proclivity for crossing roads, with some drivers reporting they would remove live tortoises from the roads to take home or to sell (Kioko et al. 2015). Also, it is known that the opportunity roads present for foraging my actually increase predator population size which can, in turn, negatively impact tortoise population size due to increased predation pressure (Loehr 2017). Thus, African tortoise populations are likely directly and indirectly threatened by roads and it remains uncertain whether certain tortoise species can sustain their populations into the future as road networks increase in density.

Biodiversity Observations is an open access electronic journal published by the Animal Demography Unit at the University of Cape Town, available at https://journals.uct.ac.za/index.php/BO/. A permanent link for an online version of this manuscript can be found at https://journals.uct.ac.za/index.php/BO/article/view/732, which includes the PDF: https://journals.uct.ac.za/index.php/BO/article/view/732/648. An HTML version can be found at http:/ / thebdi.org/blog/2019/12/24/leopard-tortoise-road-mortality.

Journal editor: Pete Laver; Manuscript editor: Pete Laver; Corresponding author: jx_baxtergilbert@laurentian.ca Received: March 23, 2019; Accepted: December 24, 2019; Published: December 24, 2019

Recommended citation: Baxter-Gilbert J, and Riley JL. 2019. Leopard tortoise (Stigmochelys pardalis) road mortality and extralimital occurrence in Western Cape, South Africa.. Biodiversity Observations 10.12:1-4

Manuscript subject: Mortality and Distribution 


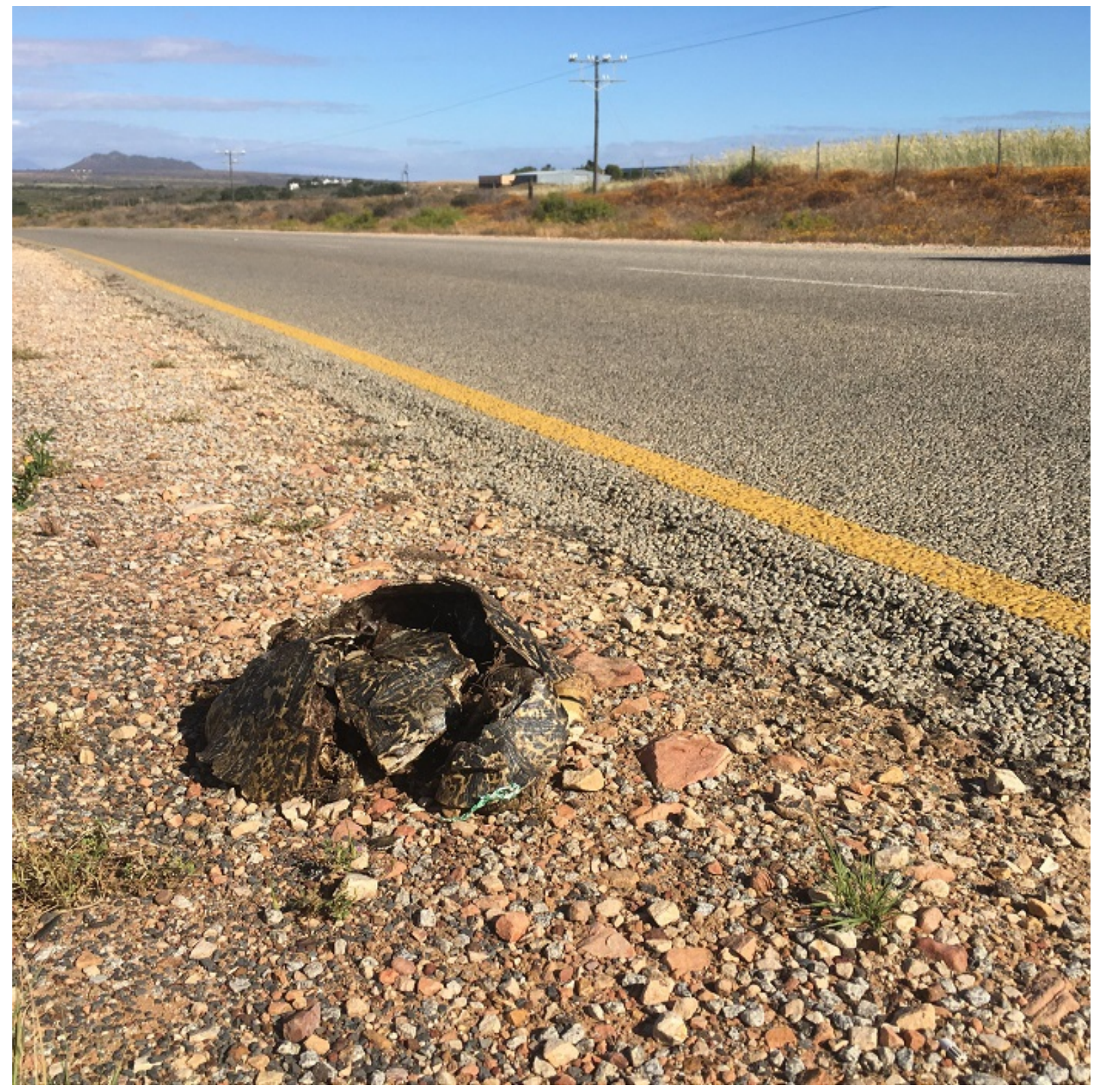

Figure 1: Figure 1. A medium-sized adult, female leopard tortoise (Stigmochelys pardalis) found dead on the road near Lambert's Bay, Western Cape, South Africa. 


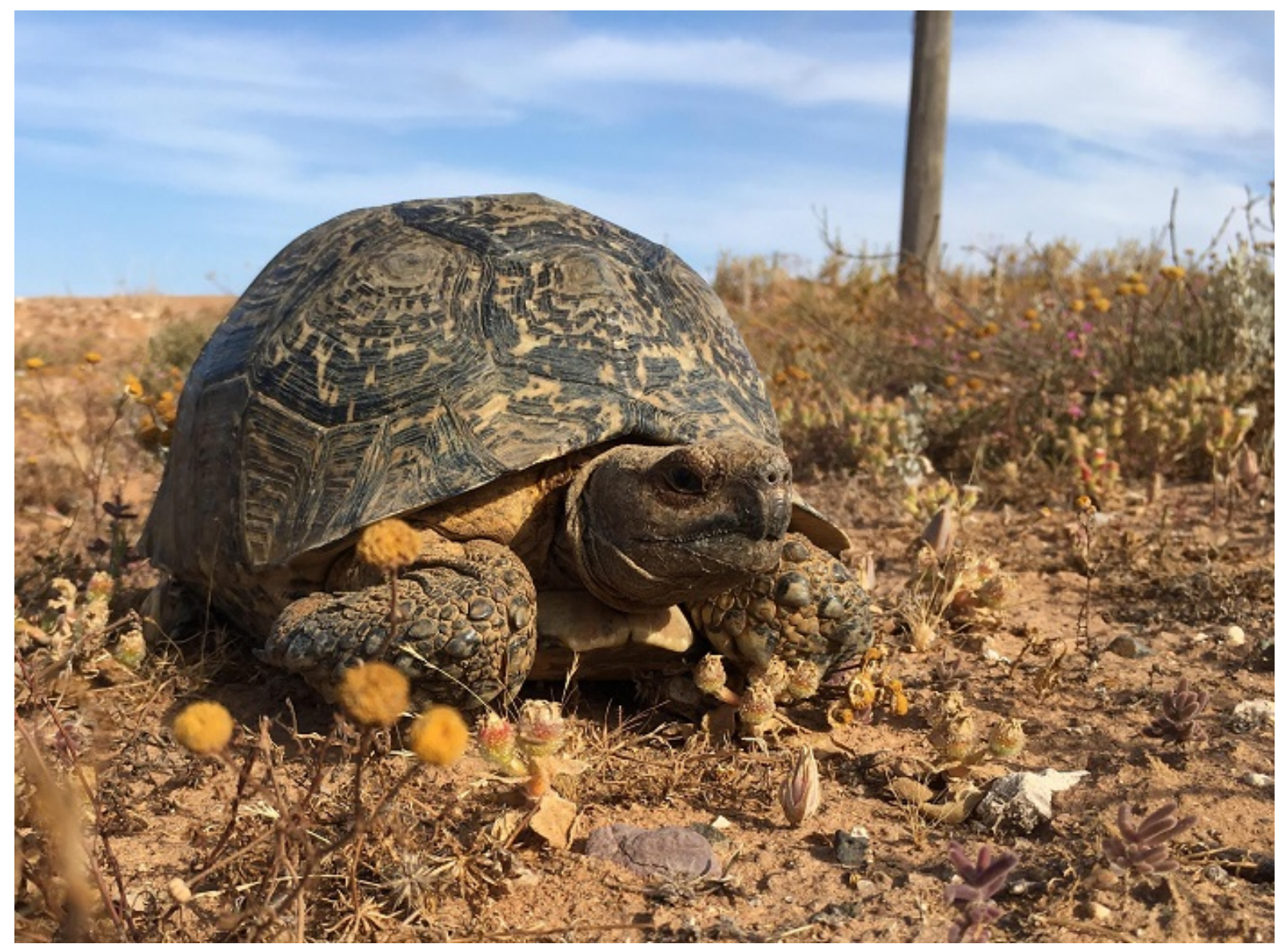

Figure 2: Figure 2. A live adult female leopard tortoise (Stigmochelys pardalis) removed from a dirt road near Lambert's Bay, Western Cape, South Africa; well outside of the species presumed native range. 
Interestingly, both of our observations of leopard tortoises on roads are well outside the species' presumed native range in the Western Cape, which ends at the Breede River $(180 \mathrm{~km}$ to the east of these observations), and over $200 \mathrm{~km}$ north of the identified introduced range (Hofmeyr and Baard 2014). It is important to note, this species is a popular pet, with escapes common, however specimens have been captured free roaming within their introduced range for the last 200 years (Hofmeyr and Baard 2014). Due to the lack of consensus as to the specific boundary line between where this species is native and where it is a domestic invasive, these observations should secondarily serve as a prompt for research into the genetic structure of leopard tortoises across their range, particularly while the species is considered widespread, common, and of low conservation concern (Hofmeyr and Baard 2014).

\section{Acknowledgments}

We would like to thank Dr. Michael Cherry for supporting the fieldtrips on which these observations were made. JBG is supported by a Centre for Invasion Biology Postdoctoral Fellowship at Stellenbosch University and JLR is supported by a Claude Leon Foundation Postdoctoral Fellowship also at Stellenbosch University.

\section{References}

Andrews KM, Gibbons JW, Jochimsen DM 2008. Ecological effects of roads on amphibians and reptiles: a literature review. In: Urban Herpetology. Mitchell JC, Brown REJ, Bartholomew B (eds). Society for the Study of Amphibians and Reptiles, USA: 121-143

Aresco MJ 2005. Mitigation measures to reduce highway mortality of turtles and other herpetofauna at a north Florida lake. The Journal of Wildlife Management 69: 549-560. DOI: 10.2193/0022-541X(2005)069[0549:MMTRHM]2.0.CO;2

Boycott RC, Bourquin O 2000. The Southern African Tortoise Book. Revised edition. O Bourquin, KwaZulu-Natal, South Africa

Dean WRJ, Milton SJ 2003. The importance of roads and road verges for raptors and crows in the Succulent and Nama-Karoo, South Africa. Ostrich-Journal of African Ornithology 74: 181-186. DOI: 10.2989/00306520309485391

Gibbs JP, Shriver WG 2002. Estimating the effects of road mortality on turtle populations. Conservation Biology 16: 1647-1652. DOI:10.1046/j.1523-1739.2002.01215.x

Hofmeyr MD, Baard EHW 2014. Stigmochelys pardalis (Bell, 1828). In: Atlas and Red List of Reptiles of South Africa, Lesotho and Swaziland. Bates MF, Branch WR, Bauer AM, Burger M, Marais J, Alexander GJ, Villiers (eds). South African National Biodiversity Institute, Pretoria, South Africa

Keevil MG, Brooks RJ, Litzgus JD 2018. Post-catastrophe patterns of abundance and survival reveal no evidence of population recovery in a long-lived animal. Ecosphere 9:e02396. DOI: $10.1002 /$ ecs 2.2396

Kioko J, Kiffner C, Phillips P, Patterson-Abrolat C, Collinson W, Katers S 2015. Driver Knowledge and Attitudes on Animal Vehicle Collisions in Northern Tanzania. Tropical Conservation Science 8: 352-366. DOI: 10.1177/194008291500800206

Loehr VJ 2017. Unexpected decline in a population of speckled tortoises. The Journal of Wildlife Management 81: 470-476. 